\title{
A revised list of alien plants for the Kruger National Park
}

\section{L.C. Foxcroft, L. Henderson, G. R. Nichols and B.W. MARTin}

Foxcroft, L.C., L. Henderson, G. R. Nichols and B.W. Martin. 2003. A revised list of alien plants for the Kruger National Park. Koedoe 46(2): 21-44. Pretoria. ISSN 00756458.

\begin{abstract}
Alien plants recorded in the Kruger National Park are listed, providing an update of species that have been recorded since the last published list in 1988. The serious consequences that invasive alien plants pose are widely recognised internationally and are regarded as the greatest threat to the Kruger National Park. It is extremely important to maintain an updated list of species to use as a reference and from which to monitor changes in the influx of invasive species. The list contains the invasive status of the plants, current impact, habitat types, biological control status and status according to the Conservation of Agricultural Resources Act (CARA), Act 43 of 1983, as amended in March 2001.

The list comprises 370 species, of which 121 are invaders and two are transformer weeds, which may cause considerable damage and alterations to the indigenous biodiversity. A total of 91 species listed herein are also listed in the CARA regulations or are proposed additions to the CARA regulations.

Key words: alien plants, invasive, species list, status, Kruger National Park.

L.C. Foxcroft and B.W. Martin, Invasive Alien Species Section, Conservation Services, Kruger National Park, Private Bag X 402, Skukuza, 1350; L. Henderson, ARC-Plant Protection Research Institute, National Botanical Institute, Private Bag X 101, Pretoria, 0001; G. R. Nichols, Geoff Nichols Horticultural Services, 8 Larch Road, Durban, 4001 Republic of South Africa.
\end{abstract}

\section{Introduction}

The species list in this paper contains reference to lists previously published by a number of authors of alien plant species recorded in the Kruger National Park (KNP). The first published list was by Obermeijer (1937), who listed six alien plant species ("troublesome weeds": Chenopodium ambrosioides L., Tagetes minuta L., Argemone mexicana L., Gomphrena celosiodes Mart., Boerhavia diffusa L., and Cocculus hirsutus (L.) Diels. (Foxcroft \& Richardson 2003), thereafter Codd (1951) indicated 32 species, Van der Schijff (1957\& 1969) indicated 43 and 76 species, respectively, and Macdonald \& Gertenbach (1988) listed 150 alien plant species. Between 1988 and 1997, the species list increased to 216 species (KNP alien plant section records). In February 1999, Nichols and Foxcroft undertook a survey in the Skukuza personnel village listing approxi- mately 243 species. The number of alien plant species in the KNP then totalled approximately 360 species, prompting a revision of the KNP alien plant list to provide a more accurate reflection of the records. Figure 1 indicates the increase in alien plant species in the KNP. The long-term average increase in alien plant species, since the first record of alien plants was made in 1937, is 5.6 alien species per year. Thirteen species have been removed from the list presented by Macdonald \& Gertenbach (1988), as information now indicates that these species are probably indigenous (Appendix 1).

\section{Presentation of the list}

Families and species, respectively, are listed alphabetically within each of the major plant groupings of Pteridophyta (ferns and fern allies), Gymnosperms, Angiosperms (Monocotyledons and Dicotyledons). 


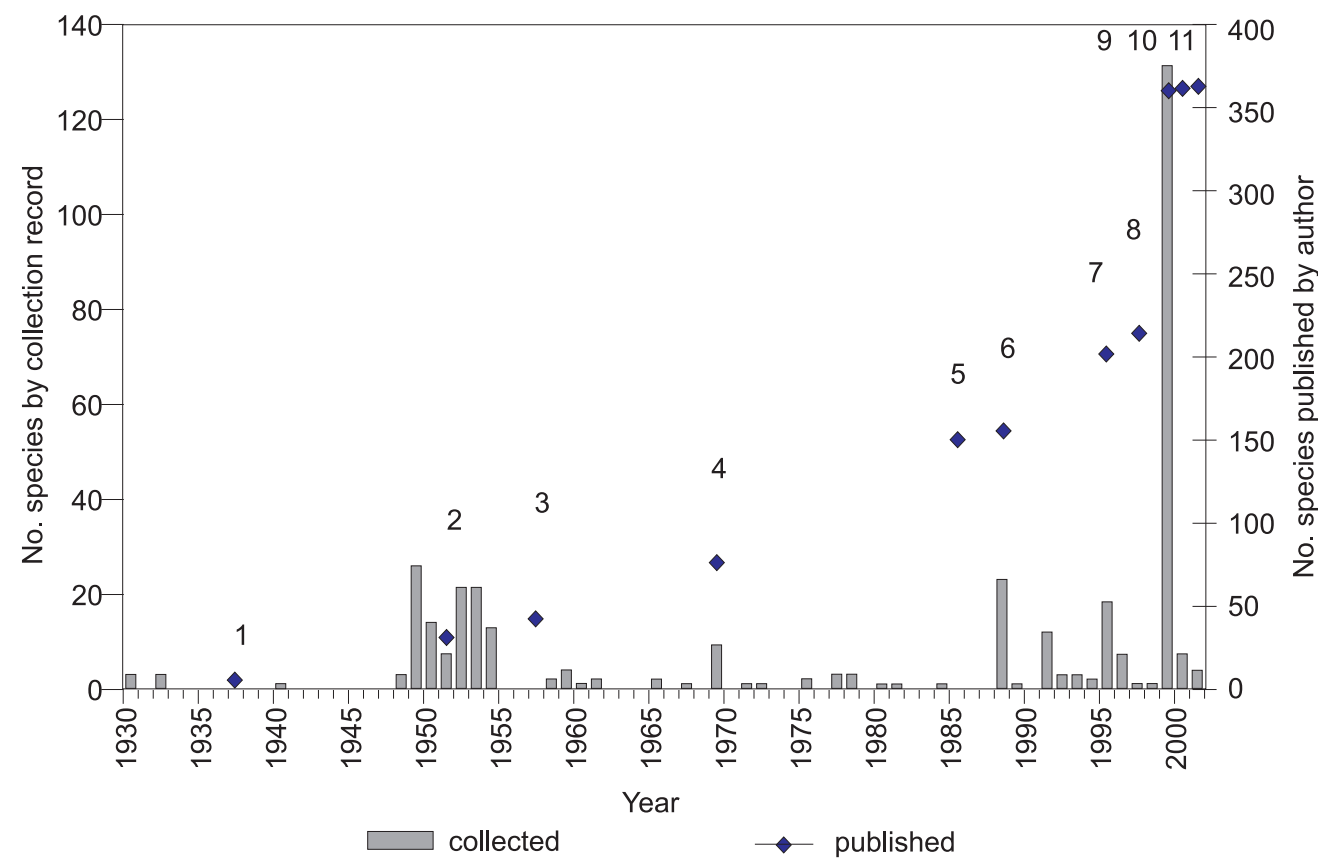

Fig. 1: The number of invasive alien plant species recorded in the Kruger National Park between 1930 and 2001. The list includes species listed according to published and other lists, as well as according to dates of collections/observations of species. For published and other species lists, the authors are indicated: 1 . Obermeijer (1937); 2. Codd (1951); 3. Van der Schijff (1957); 4. Van der Schijff (1969); 5. Gertenbach (1985); 6. Macdonald \& Gertenbach (1988); 7. Anon (1995); 8. Anon (1996); 9. Foxcroft (1999); 10. Foxcroft (2000); 11. Foxcroft (2001).

The list further provides information on the status of the weed and its current impact in the KNP, as well as its biological control and legal status for South Africa. The date provided is that of the first record for the species or when the species was first listed in publications. ' $M \& G$ ' is added to the date column to indicate plants listed in the last published list (Macdonald \& Gertenbach 1988). All plants not indigenous to the KNP lowveld have been listed in a manner similar to Macdonald \& Gertenbach (1988).

Weed status (as is currently observed in the KNP) is described using the terminology proposed by Richardson et al. (2000):

- Alien plants: plant taxa in a given area whose presence there is due to intentional or accidental introduction as a result of human activity (synonyms: non-native plants, non-indigenous plants).

- Casual alien plants: alien plants that may flour- ish and even reproduce occasionally in an area, but which do not form self-replacing populations and which rely on repeated introductions for their persistence (denoted by C).

- Naturalised plants: alien plants that reproduce consistently and sustain populations over many life cycles without direct intervention by humans (or in spite of human intervention); they often recruit offspring freely, usually close to adult plants, and do not necessarily invade natural, semi-natural or human-made ecosystems (denoted by $\mathrm{N}$ ).

- Invasive plants: naturalised plants that produce reproductive offspring, often in very large numbers, at considerable distances from parent plants and thus have the potential to spread over a considerable area (denoted by I). Where the species is considered as a potential invader, PI is added.

- Transformers: a subset of invasive plants which change the character, condition, form or nature of ecosystems over a substantial area relative to 
the extent of that ecosystem (denoted by $\mathrm{T}$ ). Where the species is considered as a potential transformer, PT is added.

Impact on the KNP is noted as the current known impact, and rated as high $(\mathrm{H})$, moderate $(\mathrm{M})$ or low (L). This information is an estimate based on records of the species in the KNP and the authors' personal experience.

The habitat types where the plants are currently observed in the KNP are: disturbed areas and roadsides denoted by the symbol (DR), villages and rest camps (V), aquatic habitats (A), riparian/riverine (R) and terrestrial/dryland habitats (TD).

Status of biological control is indicated at two levels; that taken from the national biocontrol list (Olckers \& Hill 1999); and, that for the KNP (Martin \& Foxcroft 2001) indicated by (*).

Legal status refers to the recently revised regulation 15 in terms of the Conservation of Agricultural Resources Act, 1983 (Act No. 43 of 1983):

- $\quad D W 1$ : Declared weed (category 1) are prohibited plants which must be controlled, or eradicated where possible (except in biocontrol reserves, which are areas designated for the breeding of biocontrol agents);

- DI2: Declared Invader (category 2) are mainly commercial plantation species but also plants for woodlots, animal fodder, soil stabilisation, etc., allowed only in demarcated areas, by permit holders, under controlled conditions and in biocontrol reserves;

- DI3: Declared Invader (category 3) are mainly ornamental species that may no longer be planted (except with special written permission), nor may there be trade in propagative material. Existing plants may remain but must be prevented from spreading.

All three categories of plants are prohibited within $30 \mathrm{~m}$ of the 1:50 year floodline of watercourses or wetlands, unless exemption is obtained. The full regulations and species list are given in Henderson (2001).

\section{Discussion}

A total of 370 alien plant species are listed and contain some subspecies, forms and varieties. Of the list, 2 species $(0.5 \%)$ (Lantana camara L. and Opuntia stricta (Haworth.) Haworth.) are transformers, 125 $(33.8 \%)$ are invasive and $223(60.2 \%)$ are either casual aliens or naturalised species, as

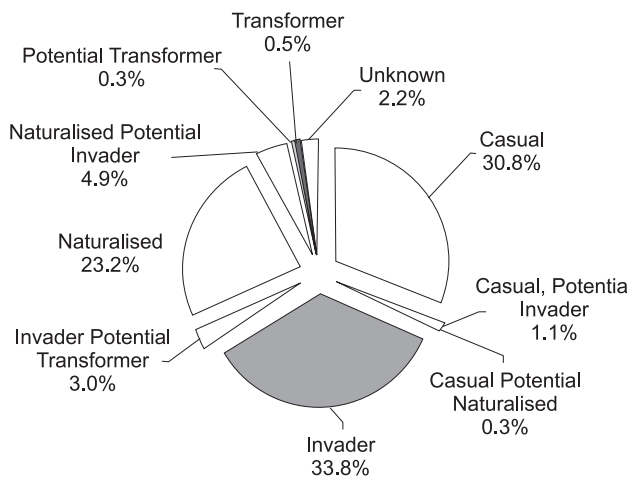

Fig. 2: Weed status of alien plant species.

is indicated by Fig. 2. The basic under-riding principle of the South African National Parks (SANParks), "to preserve biodiversity in all its natural facets and fluxes" (Braack 1997 ) is directly violated by the introduction, whether intentional or accidental, of alien organisms, and according to definition, indicates the requirement to remove or control all alien species. In practice, the control of prioritised transformer and invader species, to acceptable limits of abundance, is the most likely scenario. At this minimal level of abundance, the impact on biodiversity (as described by Noss 1990) is hoped to be minimal.

Macdonald \& Gertenbach (1988) stated that the increase in number of alien plant species recorded for the KNP was probably due to increased collecting and awareness between 1937 and 1983. Further increase may also be ascribed to increased tourism (Macdonald 1988), which has unintentionally brought in seeds from other infested parts of the country as well as increased infestation of the lowveld. Infestations and new species may also have arisen due to the considerable increase in size of towns such as Nelspruit and others along the escarpment, over the past 50 years.

Although Macdonald \& Gertenbach (1988) state that 10 species had been eradicated, at least four of these (Senna didymobotrya, 


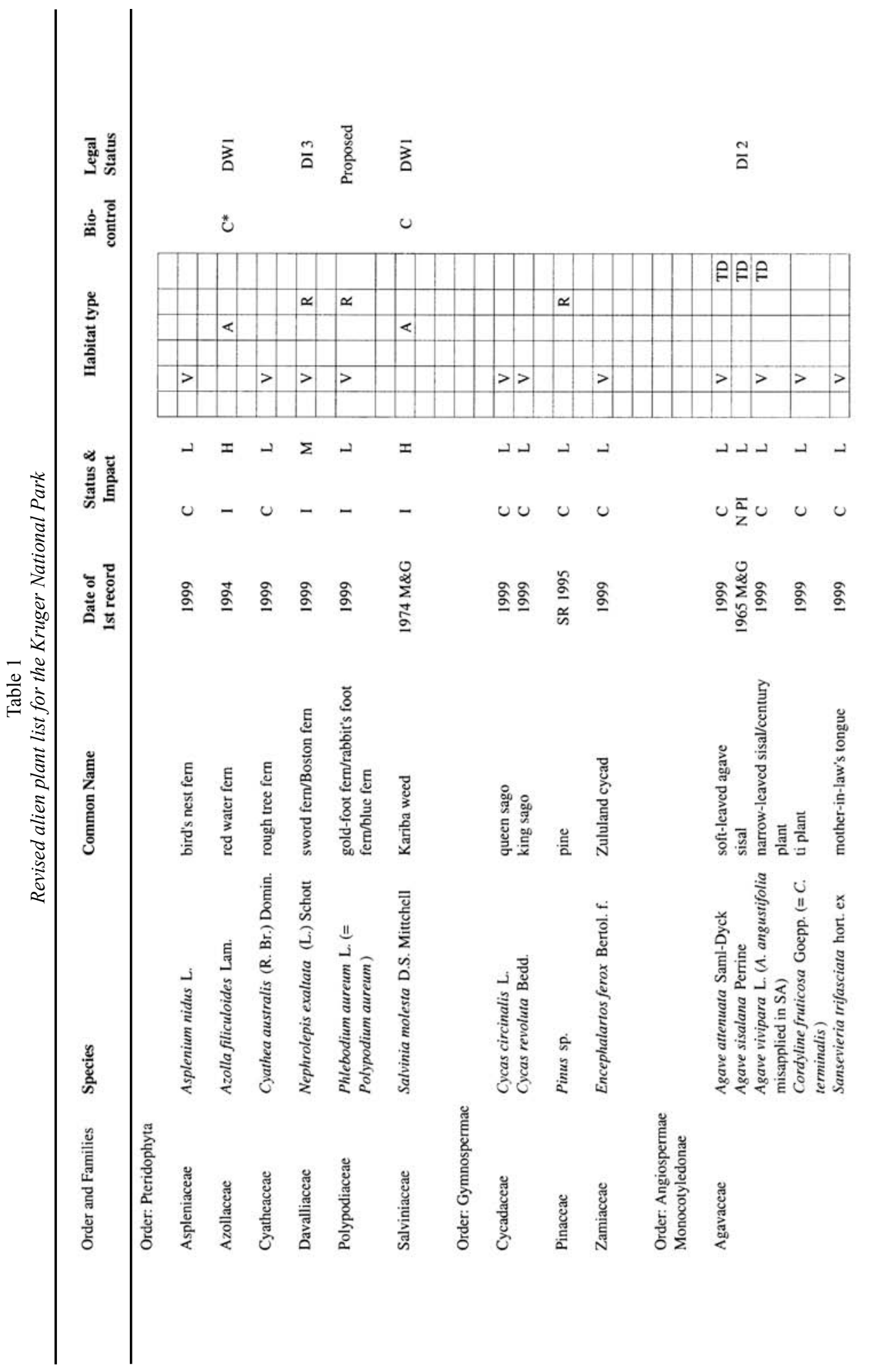




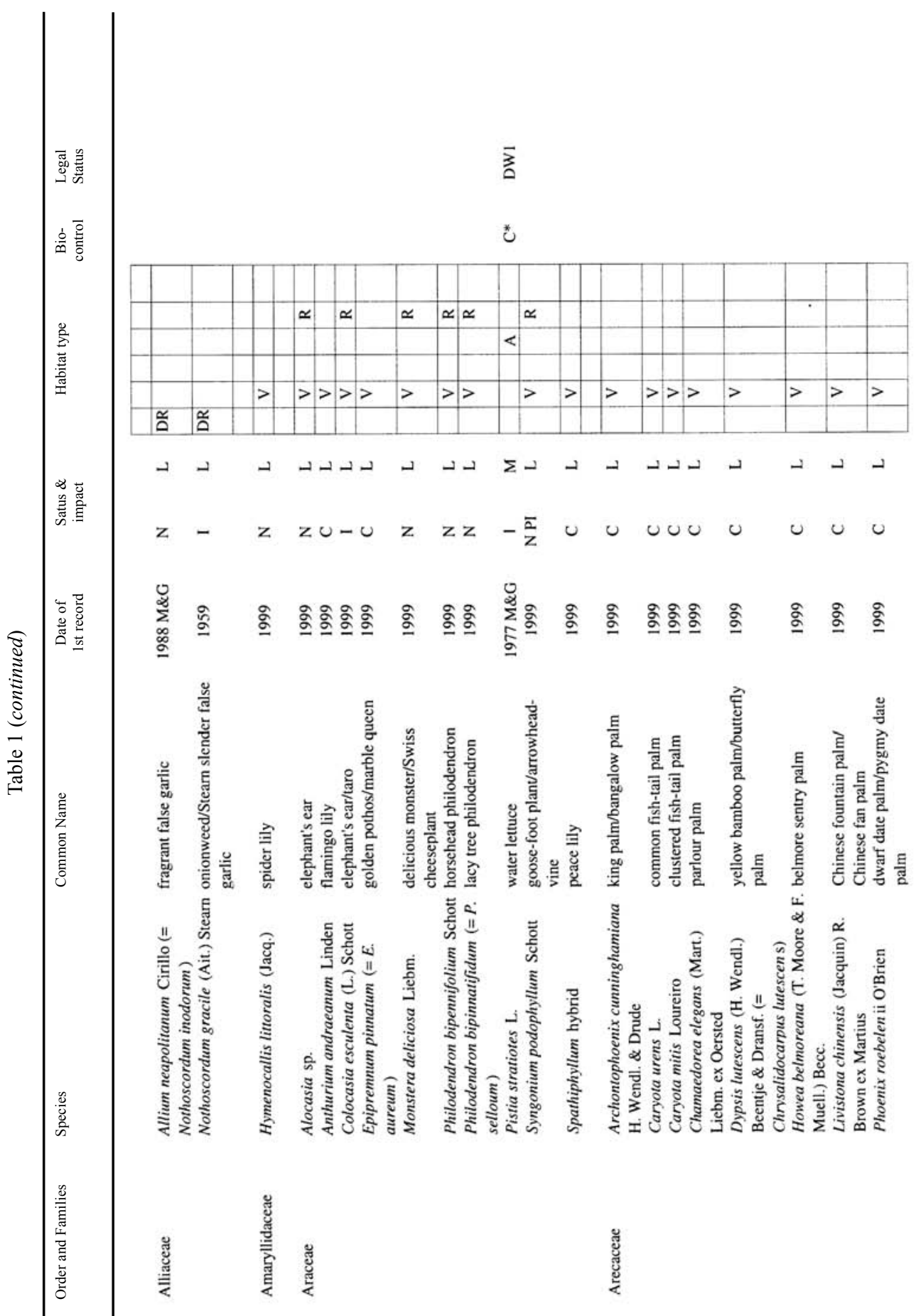




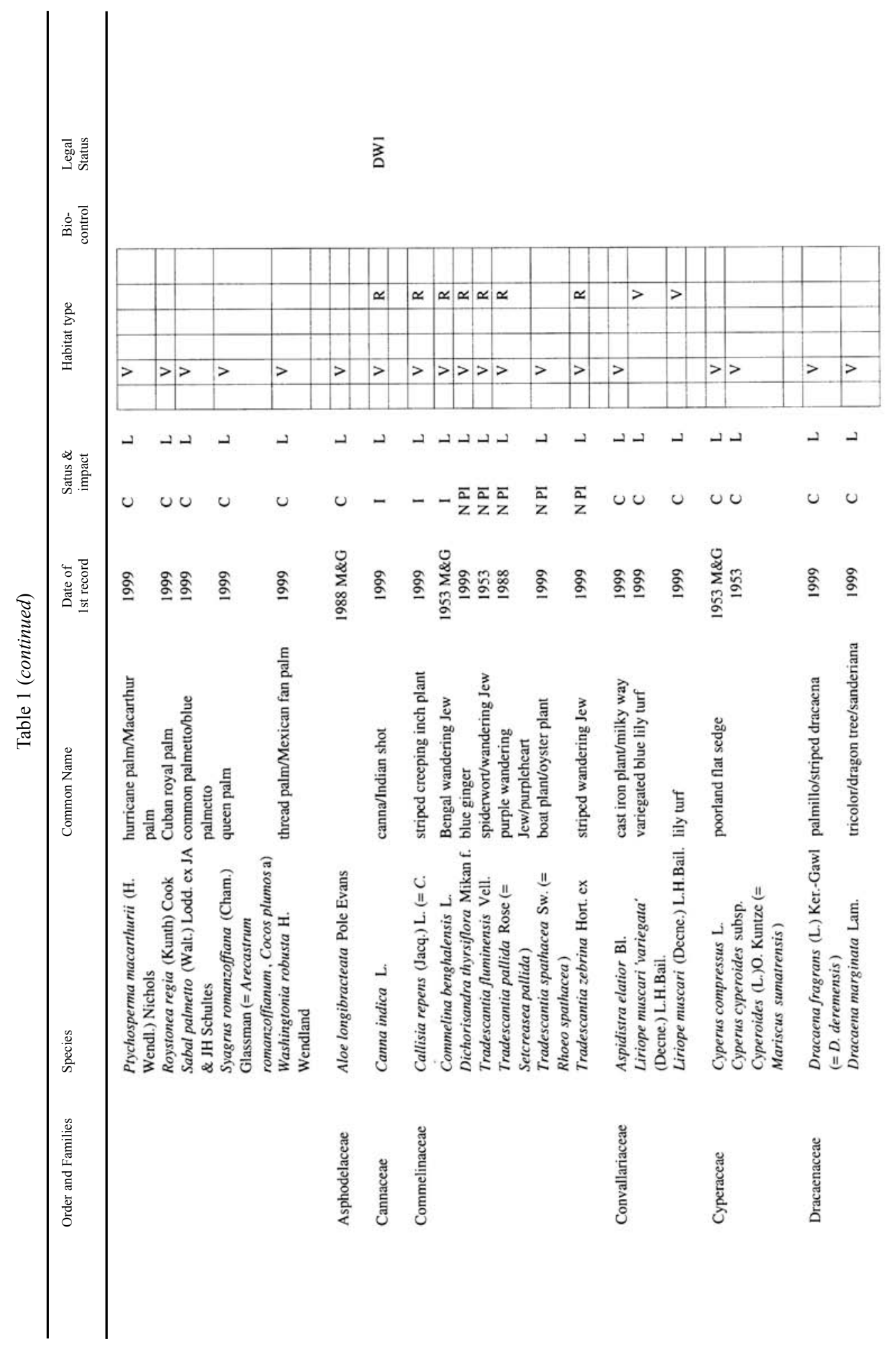




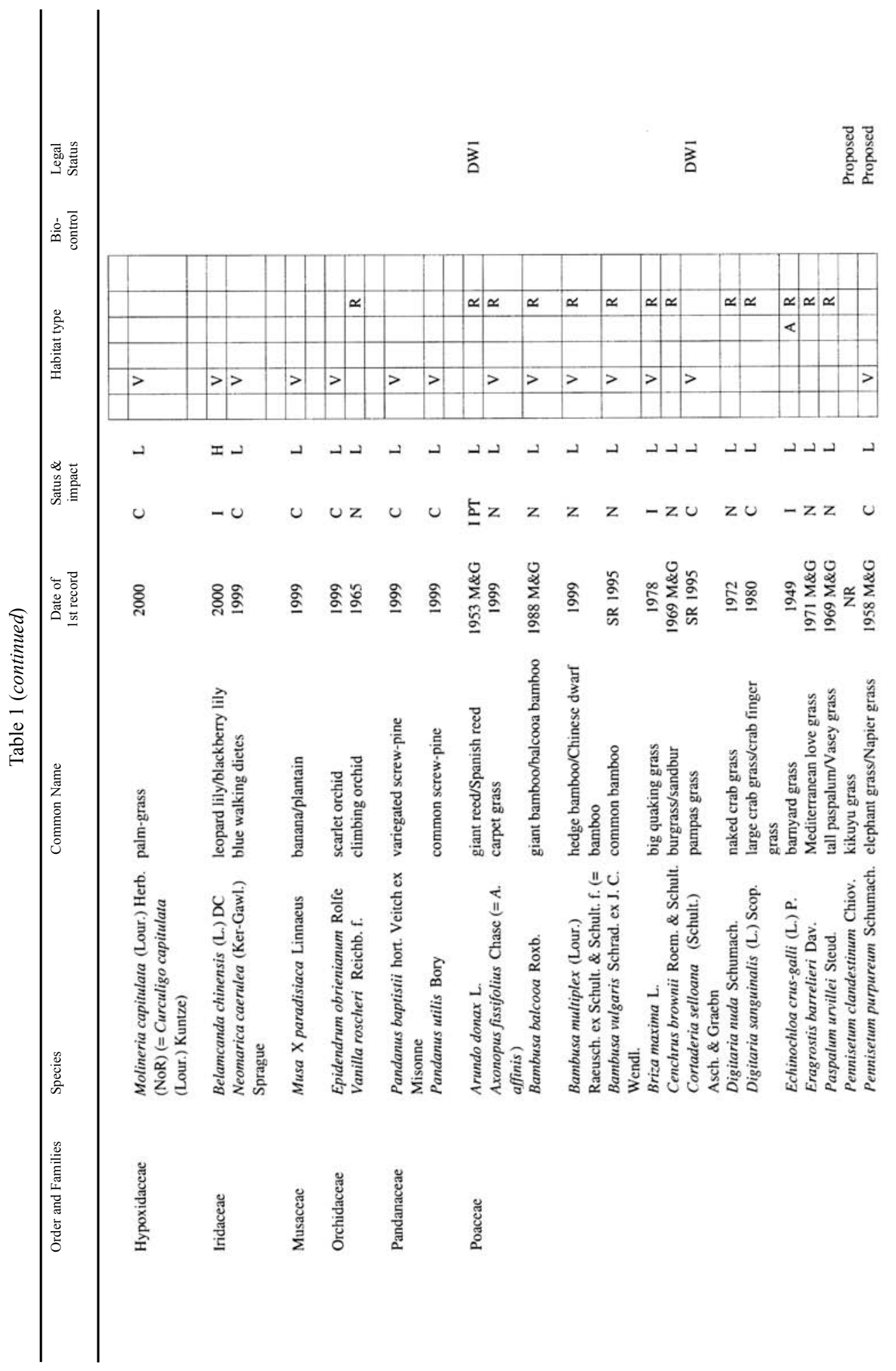




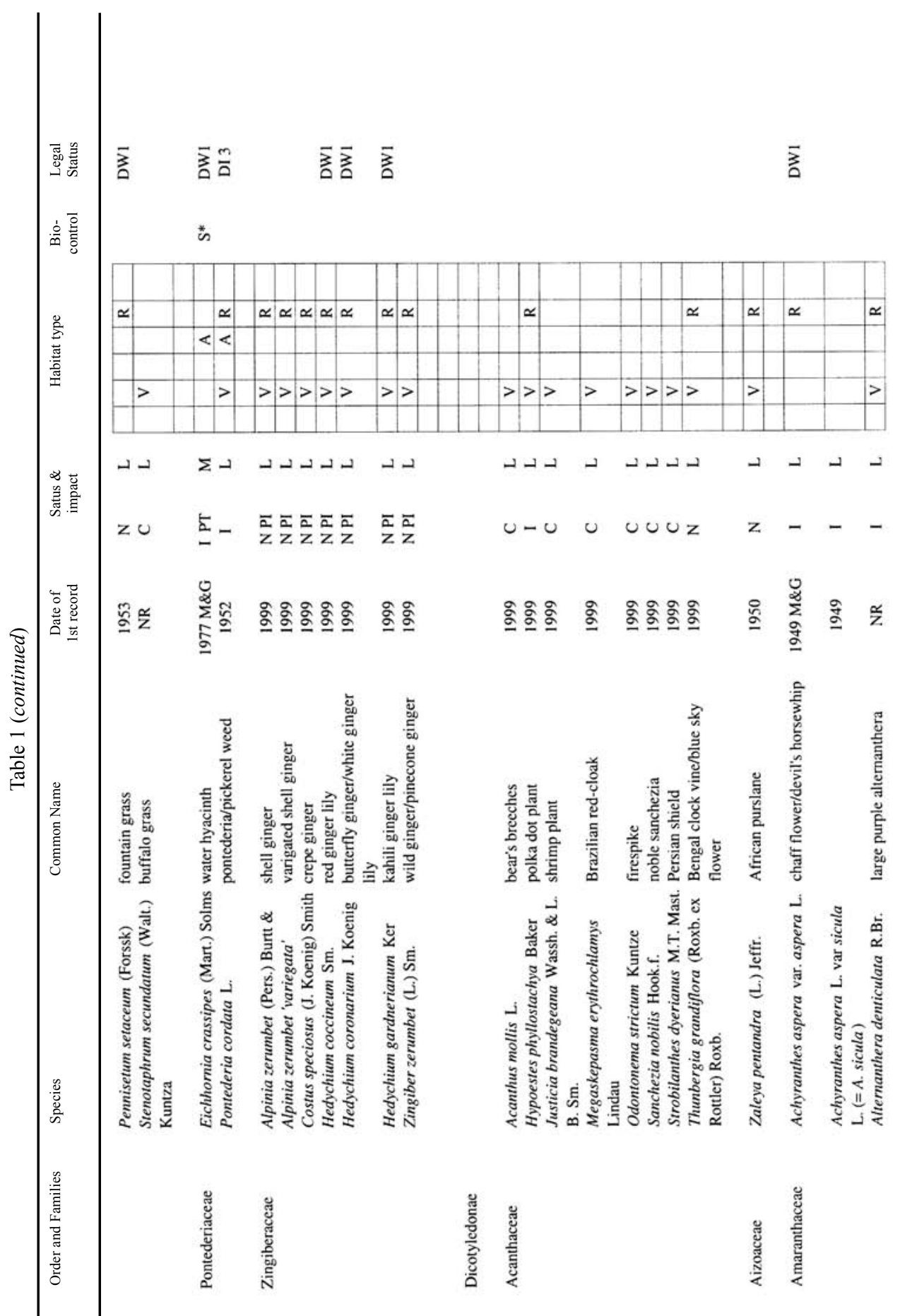




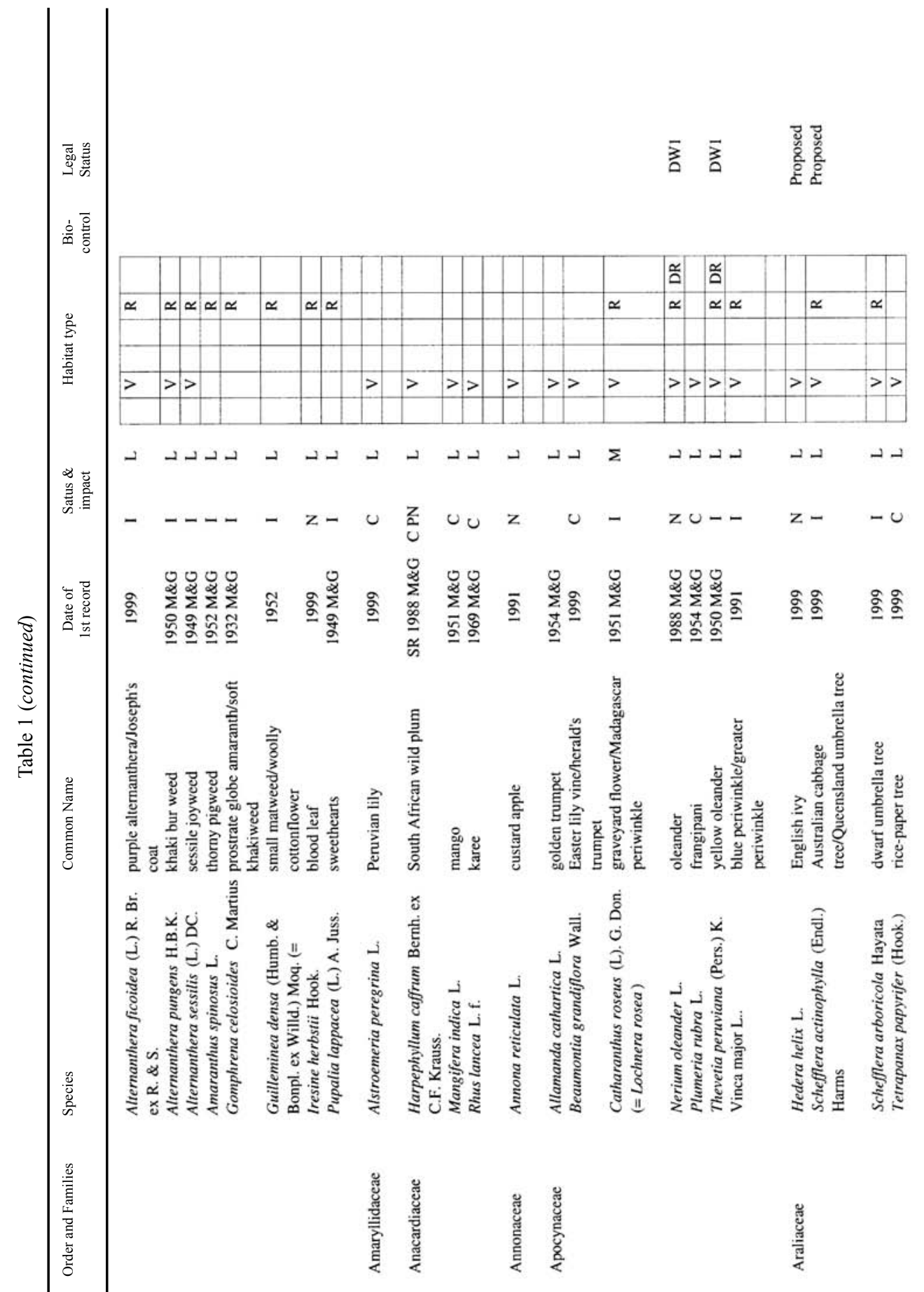




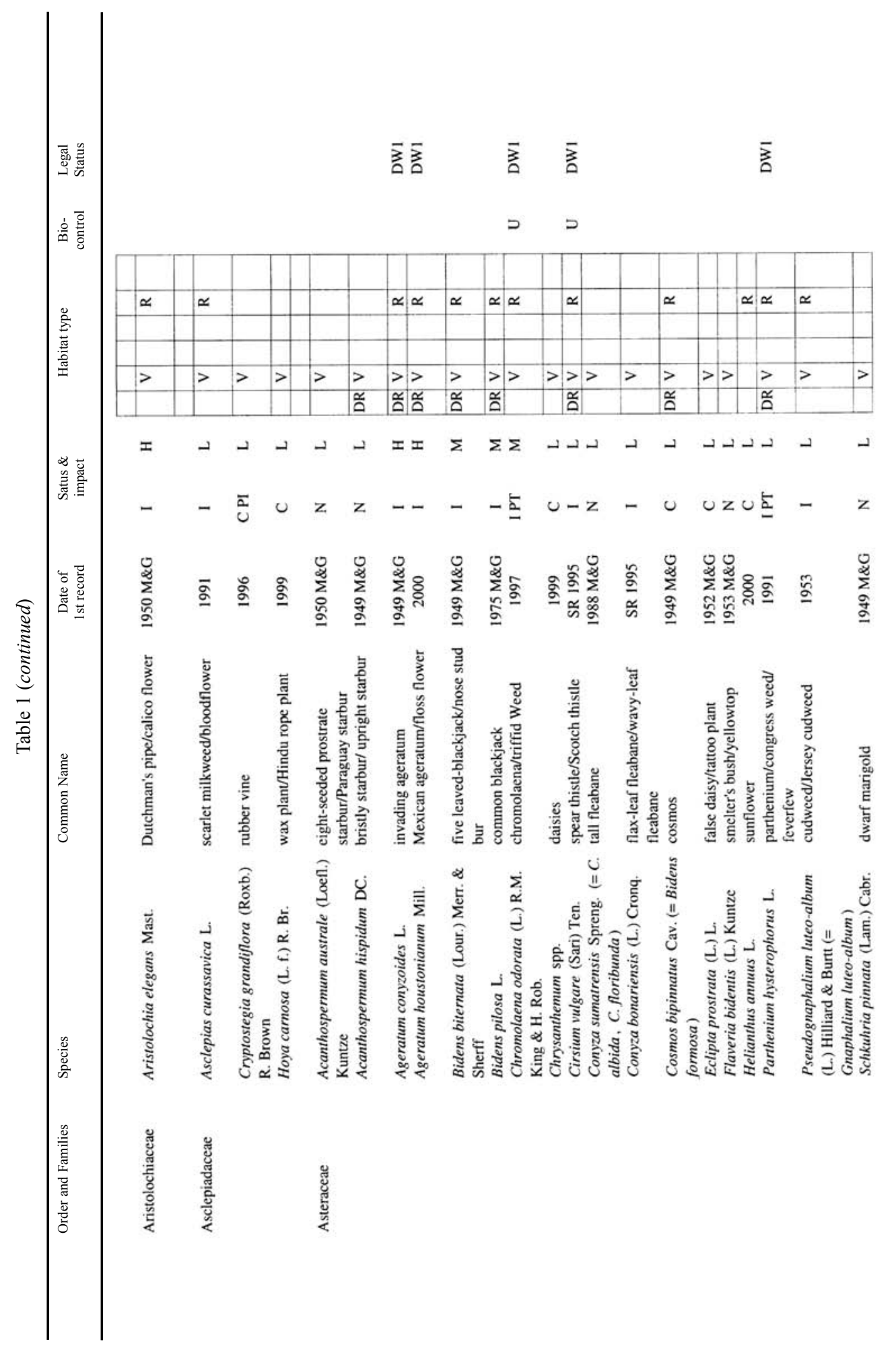




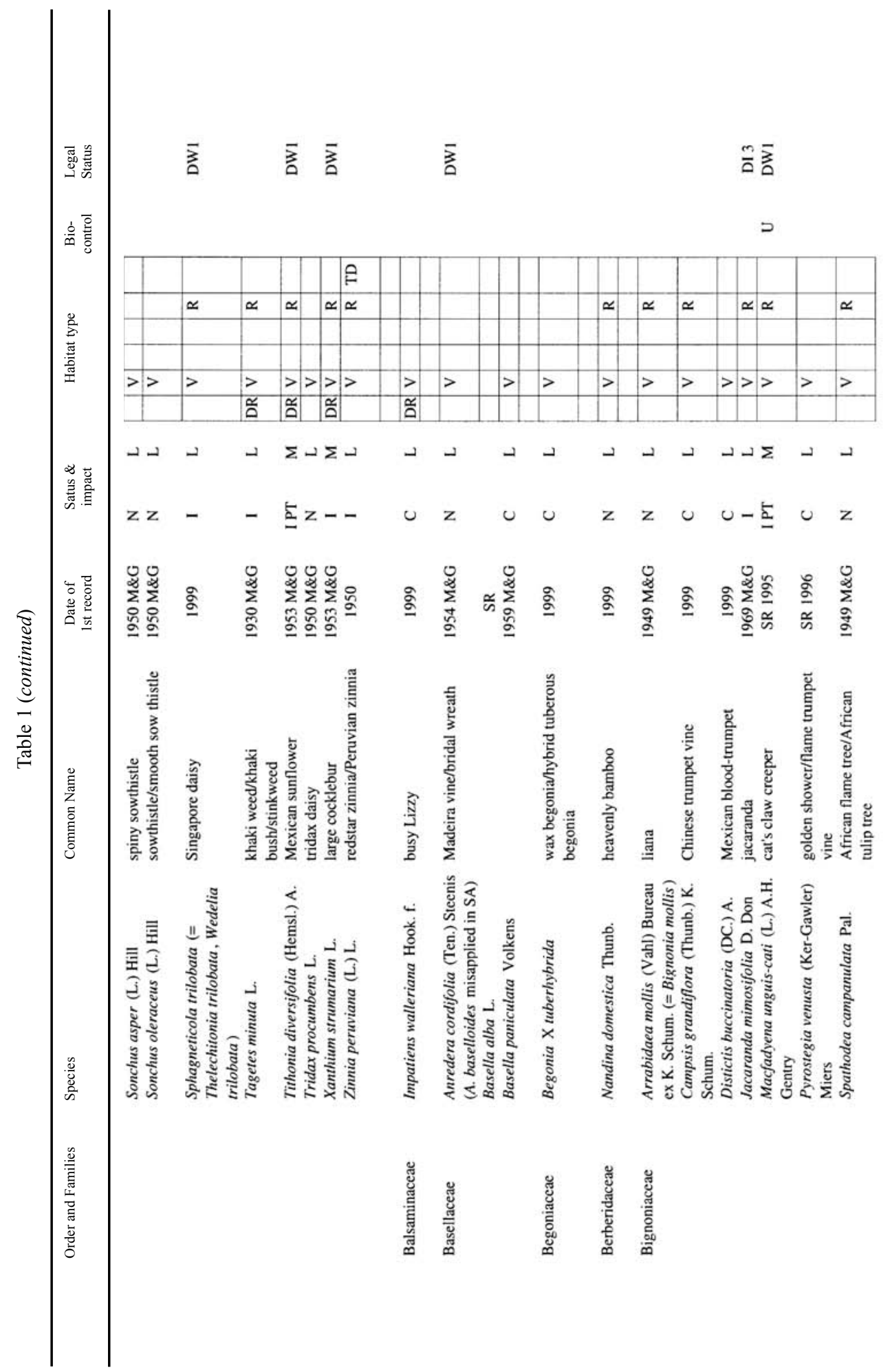




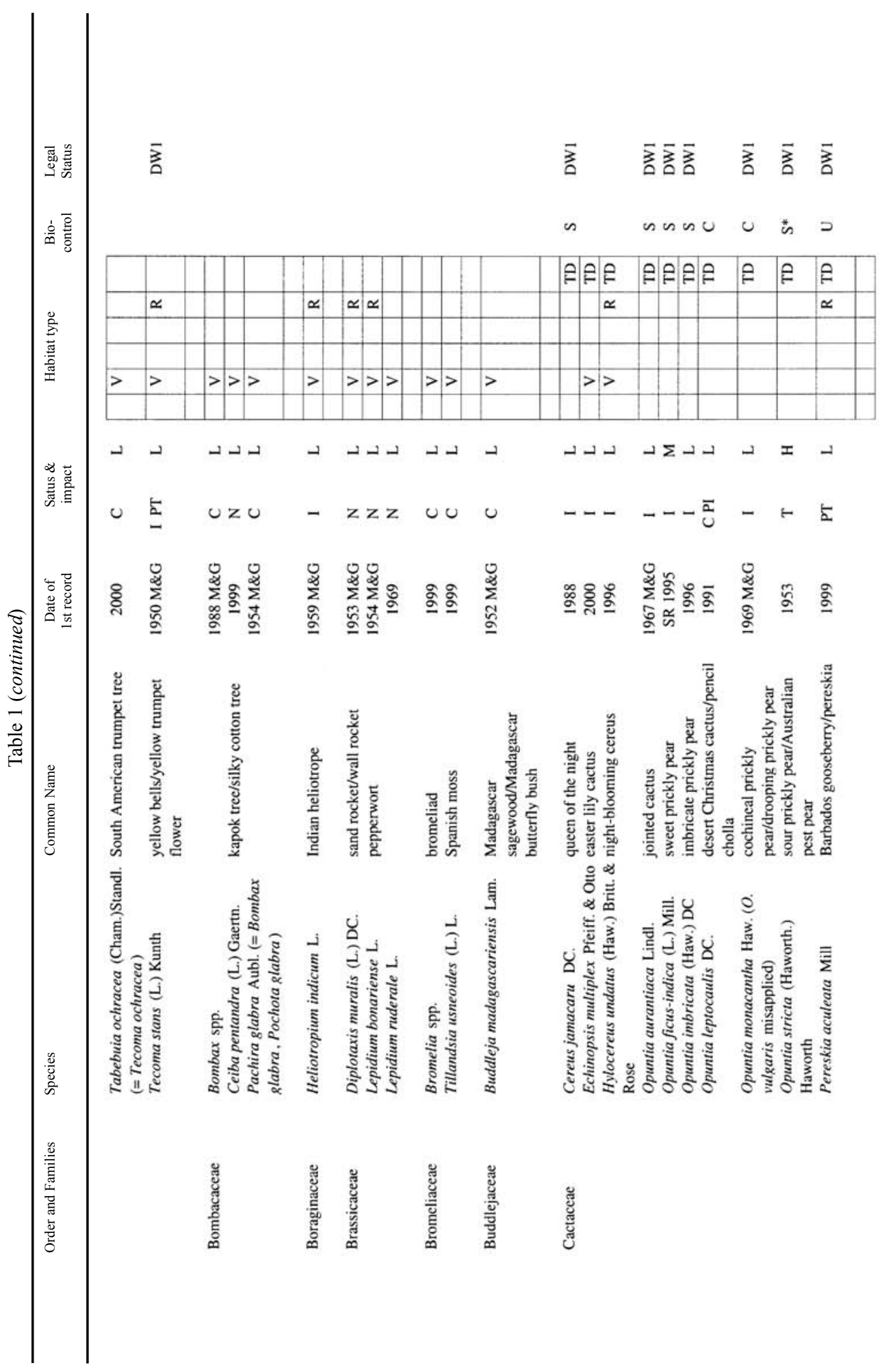




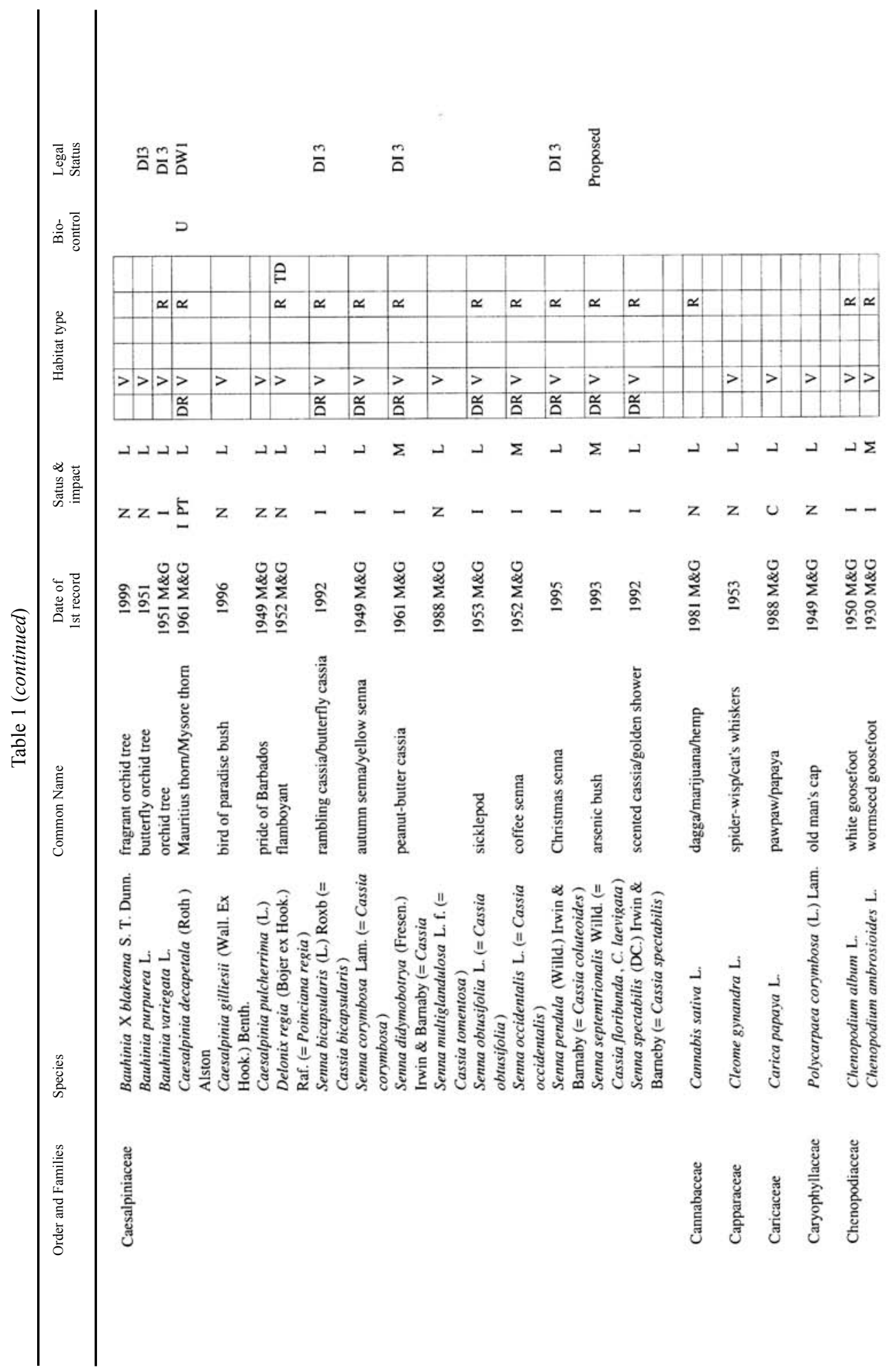




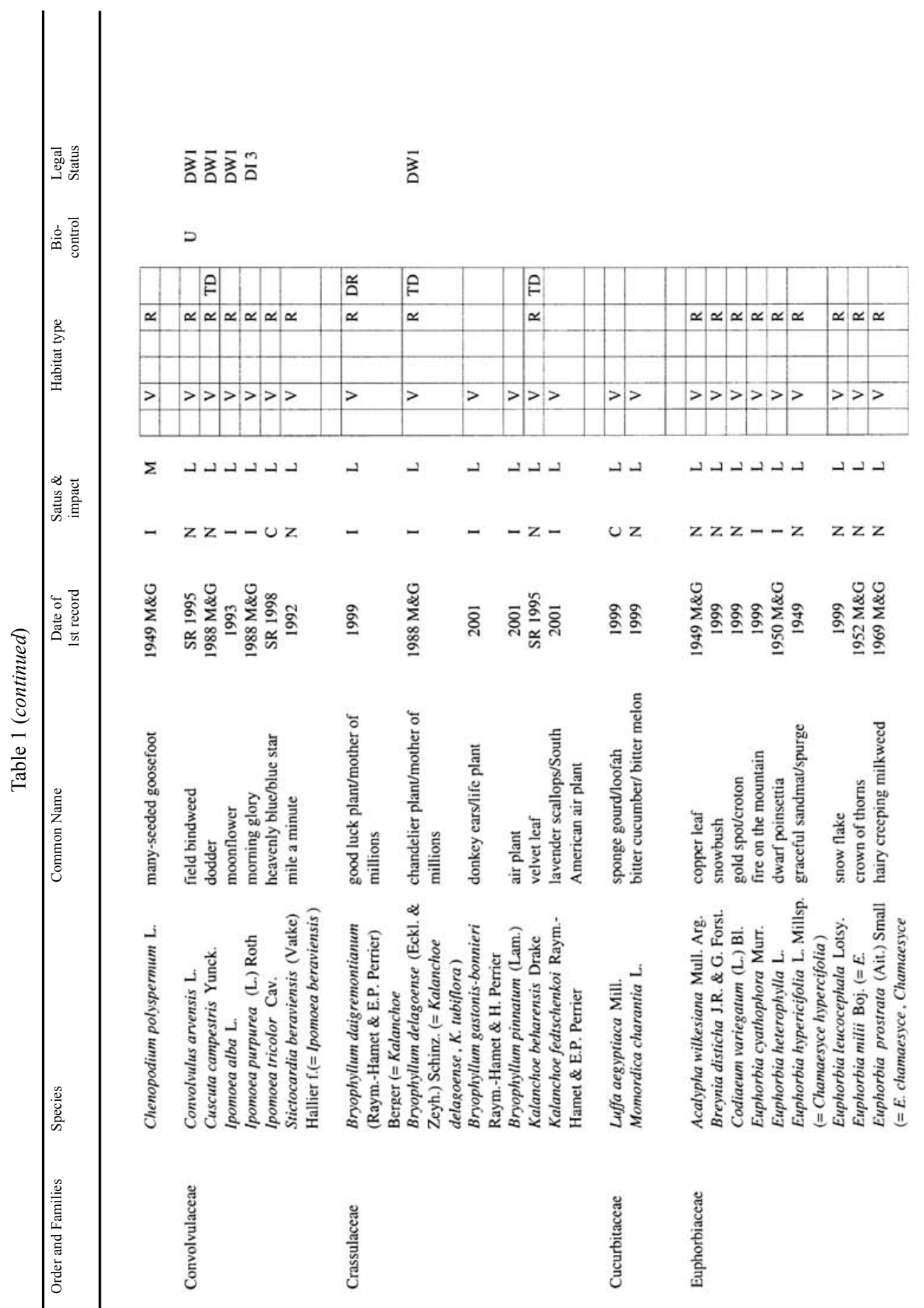




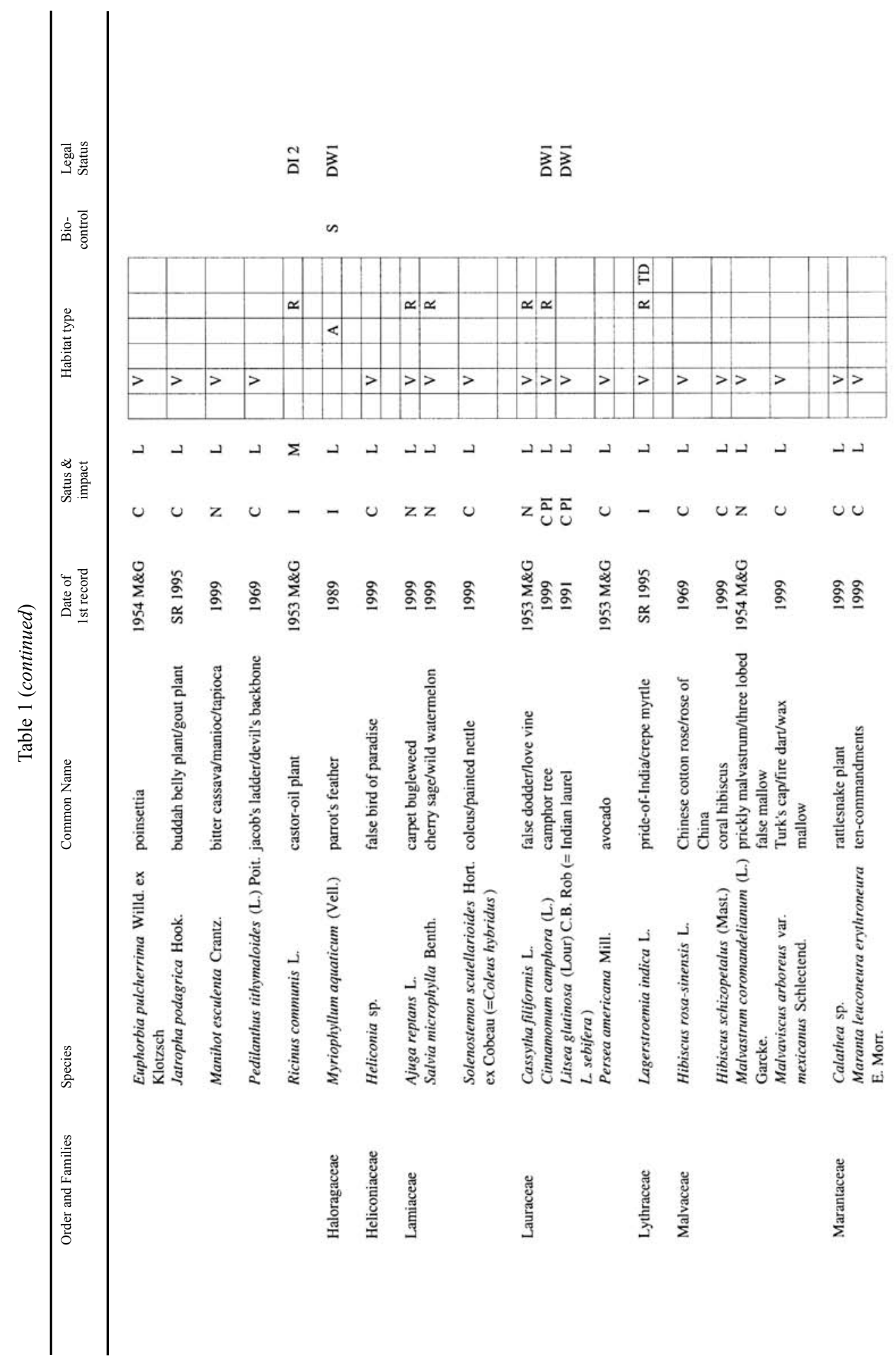




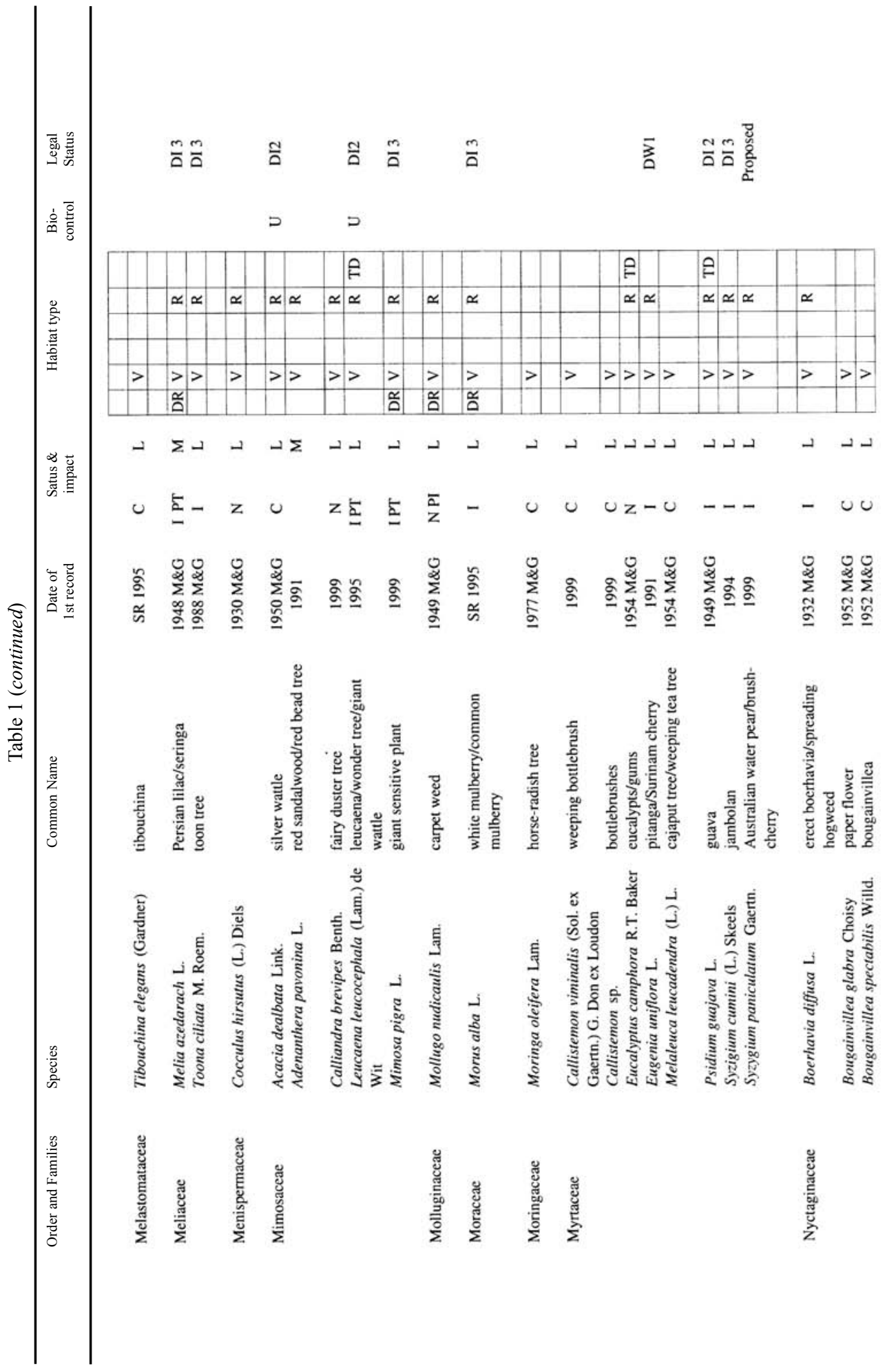




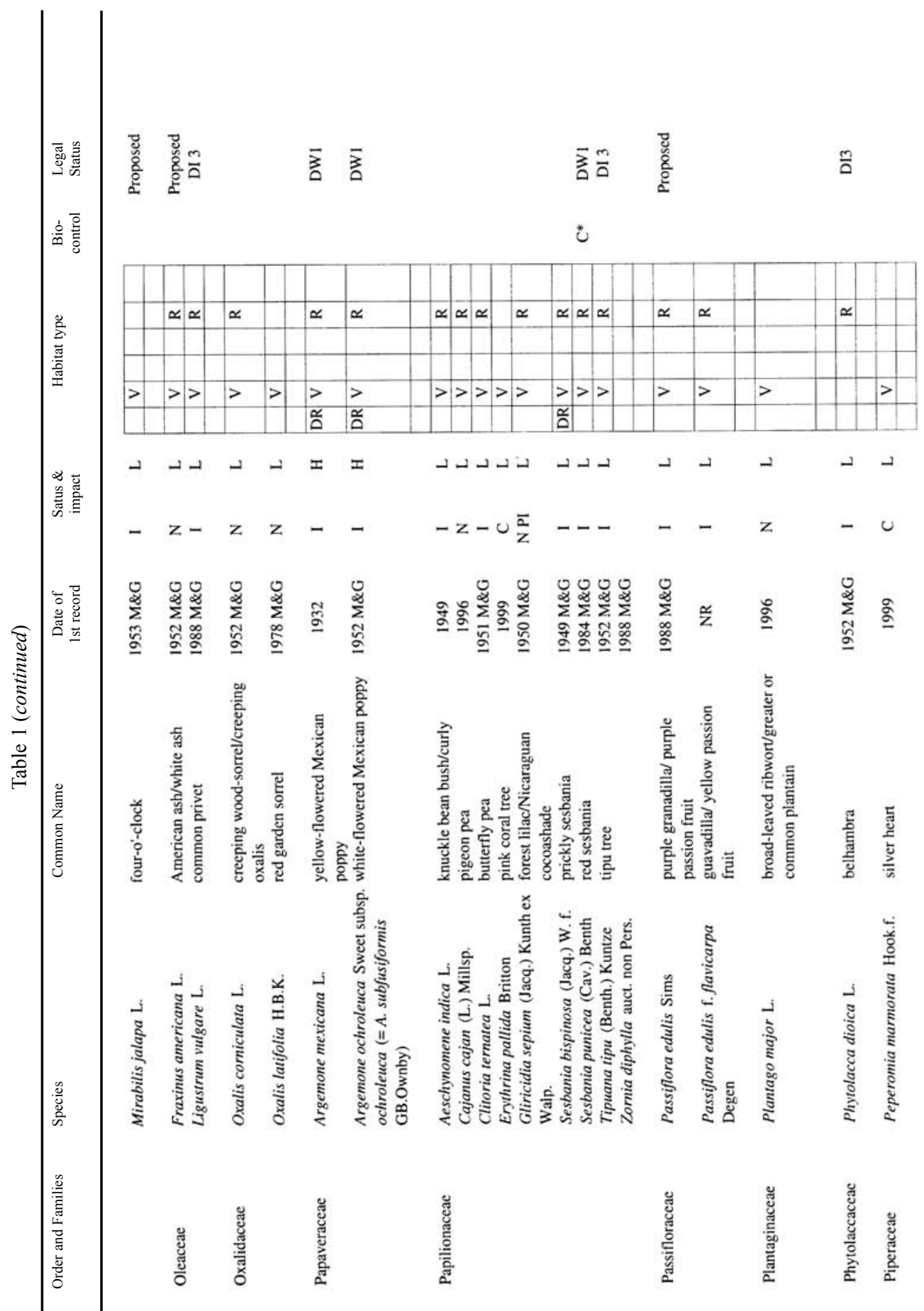




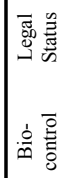

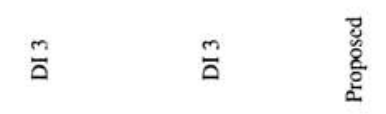

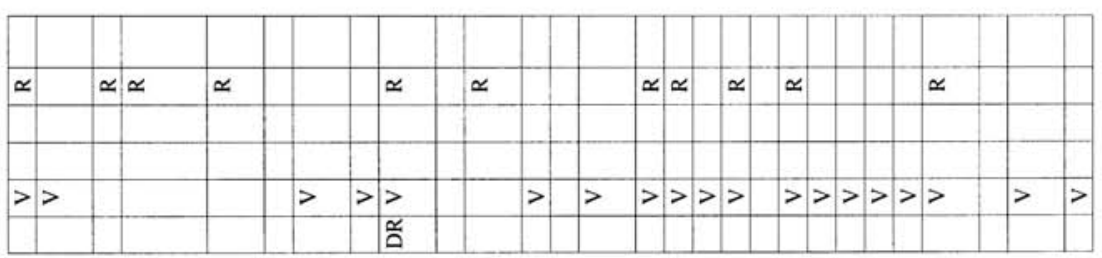

$-0 z z \quad z \quad z \quad z z-0 u \bar{a}-u--z u z u \bar{z} u \quad u$

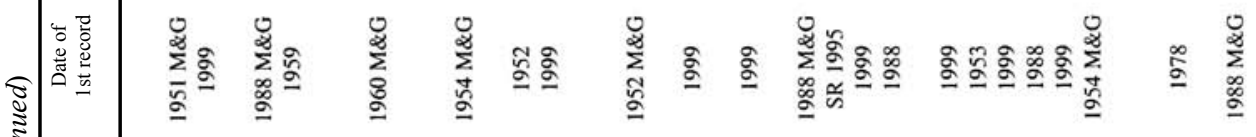

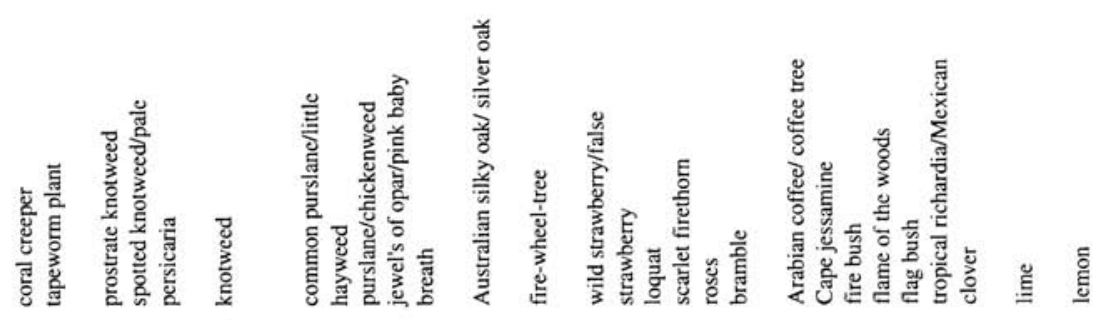

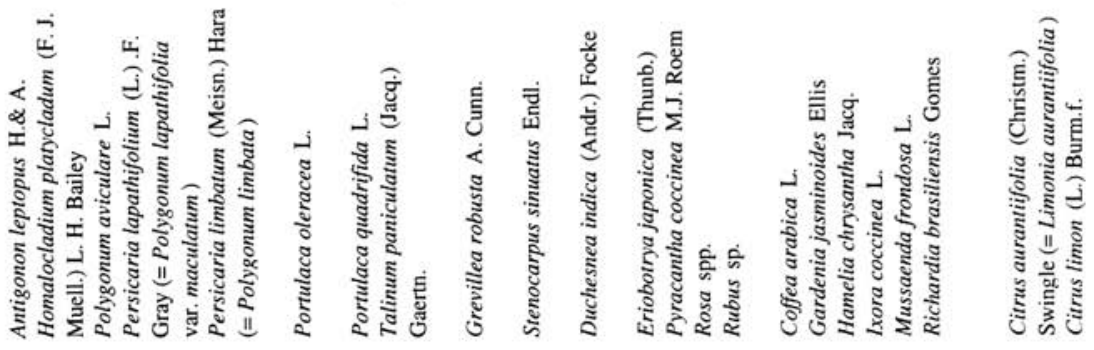

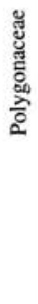

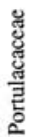

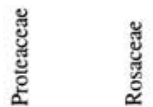

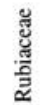

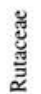




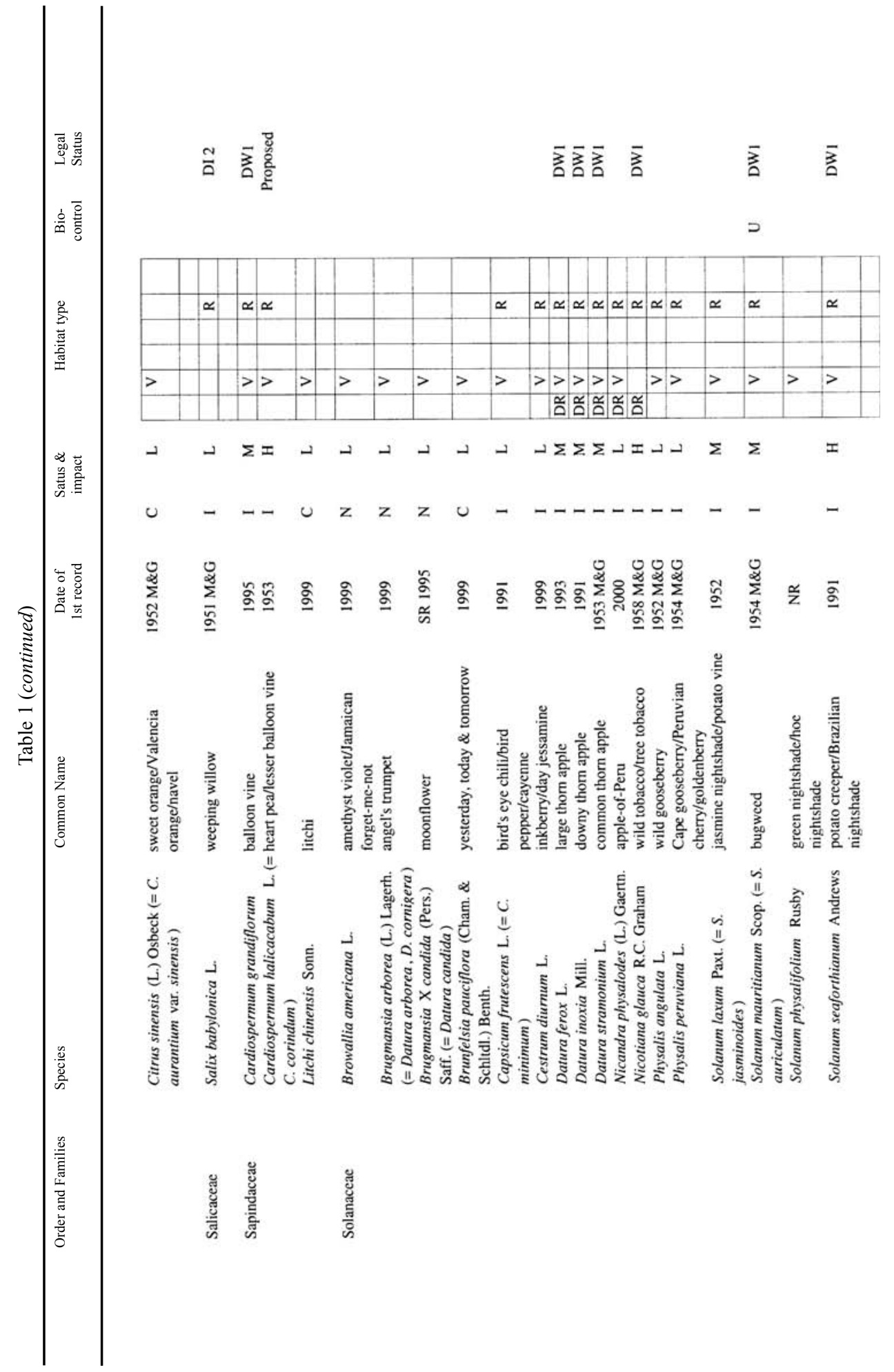




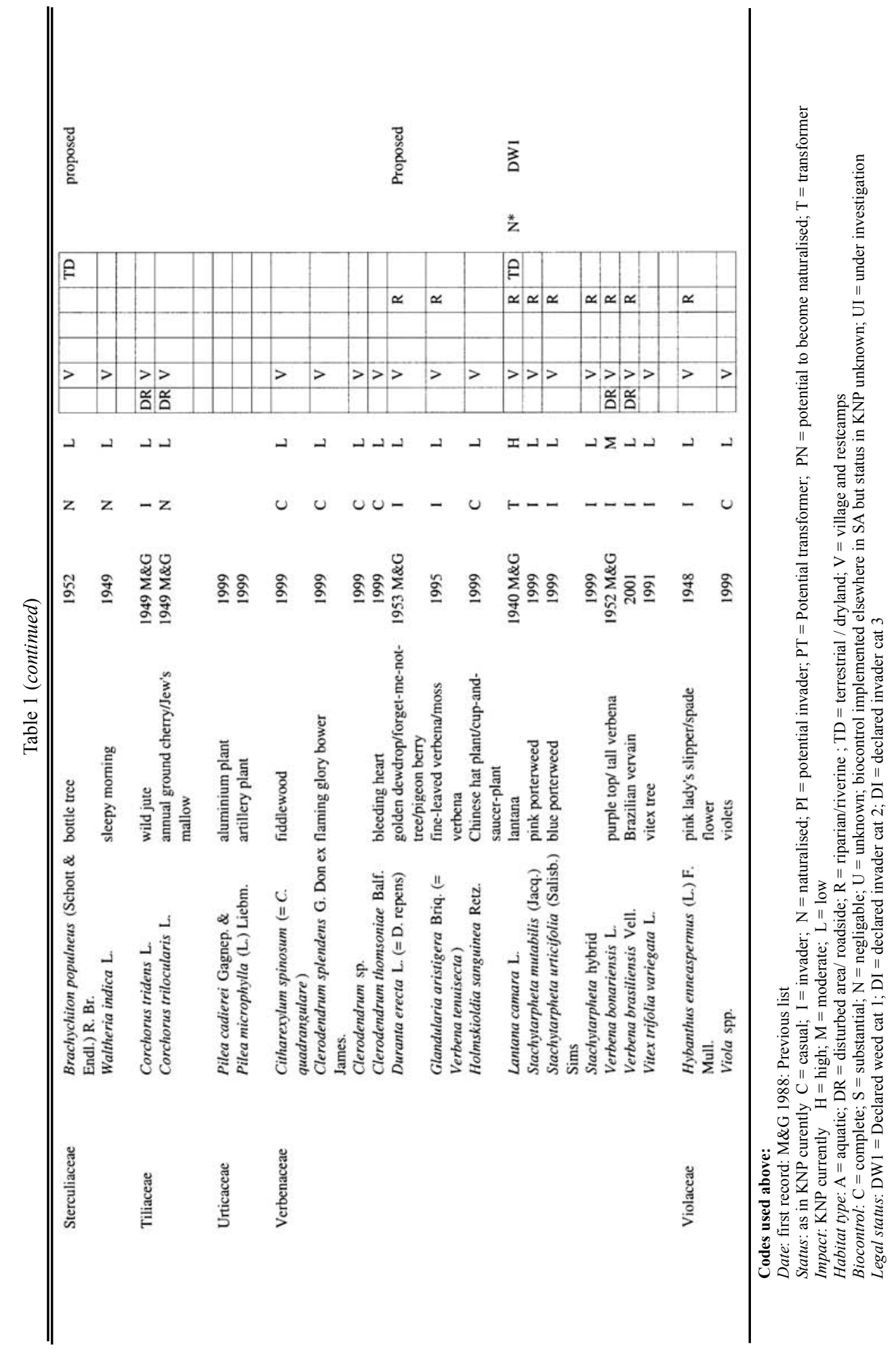


Nicotiana glauca, Tecoma stans and Ipomoea purpurea) are frequently found in the rivers. They have either re-invaded the KNP or were never eradicated in the first instance. Nicotiana glauca appears to have long-term cycles, where plants flourish along the Olifants River and then for a number of years disappear.

Two more species are present despite having been reported as eradicated. Salvinia molesta, first recorded in the KNP in 1974 (Joubert 1986) was chemically controlled over a long period, and despite being recorded as eradicated a number of times (Joubert 1986) was reported in 1985 on the Sabie River at Lower Sabie rest camp. Biological control was released on the Sabie River in 1992, and the infestation is now under complete biological control. The infestation recorded at Mtshawu Dam (near Pretoriuskop) in 1974 had biological control released in 1995 (Lotter 1997), but was sprayed chemically soon afterwards, and then aggressively controlled using herbicide from 1997 to 2000, with small isolated plants still occasionally being found. However, during 2000-2001 the plants re-infested the pool below the Mtshawu Dam wall and a decision was taken to release biological control agents on the infestation. Eight months after releasing the biocontrol agent Cyrtobagous salviniae below the Mtshawu Dam wall, the plant population crashed and remains clear of $S$. molesta. Macdonald \& Gertenbach (1988) also reported that Solanum mauritianum was first reported along the Crocodile River and was either eradicated or later failed to be reported as present along the river by officials from Skukuza. This indicates that, for a reserve the size of the KNP, the likelihood of a species being eradicated is remote once listed, and it may appear in another area at a later stage. Furthermore, the large infestations of most of these weeds on the boundaries of the KNP make it unlikely that only a few plants will enter the KNP and re-invasion by the plants is inevitable.

Evidence to prove the lag phase and our limited knowledge of the ability of alien plants to become invasive is borne by the listing of
43 species by Macdonald \& Gertenbach (1988) as non-invasive. Of these species, 17 are now well-known invasive species, while seven have since become invasive in the park. In a national park, which aims at the protection of indigenous biodiversity, policy should rather err on the side of caution. The removal of all alien species accompanied by the replacement thereof with indigenous species should be promoted. Although a species may not, at a single point in time, exhibit a tendency to invade, the lack of knowledge of the species and the long phase that is often found to prelude an explosion in the distribution of invasive species, places most species in an unknown category. This may result in serious, often immense, insidious and irreversible problems at a later stage (McNeely 2000), as species enter a rapid growth phase.

The habitat invaded indicates that the vast majority of the species occur, or occurred, in the staff villages or rest camps (320 species) and is of concern (Fig. 3). Disturbed/roadside areas are invaded by 40 species, terrestrial/dryland by 27 species, riparian by 191 species and aquatic areas are invaded by seven species. A notable example in the KNP of a species intentionally introduced and then escaping into the surrounding areas is that of $O$. stricta. Assumed to have been introduced into the KNP during the 1950s, probably as an ornamental garden plant in

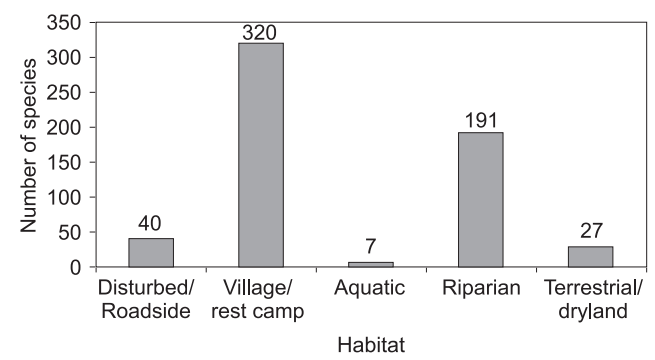

Fig. 3: Number of alien plant species per habitat type (some species may occur in more than one habitat type) 


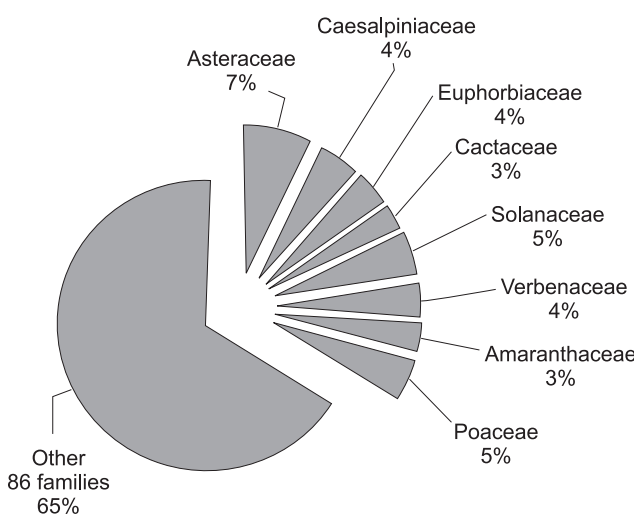

Fig. 4: Families of alien plant species in NKP.

Skukuza personnel village, O. stricta was reported by Lotter \& Hoffmann (1998) to cover an area of 30000 ha around Skukuza. Currently, the management area of $O$. stricta is approximately 66000 hectares, with a number of outlying invasions in the Tshokwane area, Nyamundwa dam and near the Mtshawu and Sabie River confluence. Opuntia stricta is also an example of the problems associated with poor record keeping and incorrect identification. Thought to have been first recorded in the KNP by Obermeijer in 1953 (Lotter \& Hoffmann 1998, cite Zeller 1996), the first record of $O$. stricta being recorded by name was in the KNP alien plant sections records in 1995 . No indication was made of the observer or date. However, Brynard \& Pienaar (1960) refer to experiments on $O$. vulgaris $(=O$. monacantha) in the Skukuza area, and it is likely that these plants were in fact $O$. stricta. Opuntia monacantha $(=O$. vulgaris $)$ was however recorded by Zeller (KNP alien plant sections records, 1996) in Orpen rest camp in 1992, and also by van der Schijff (1957) at the Komati River and Shilova (Mooiplaas ranger section).

Examination of the plant list indicates the total number of plant families represented is

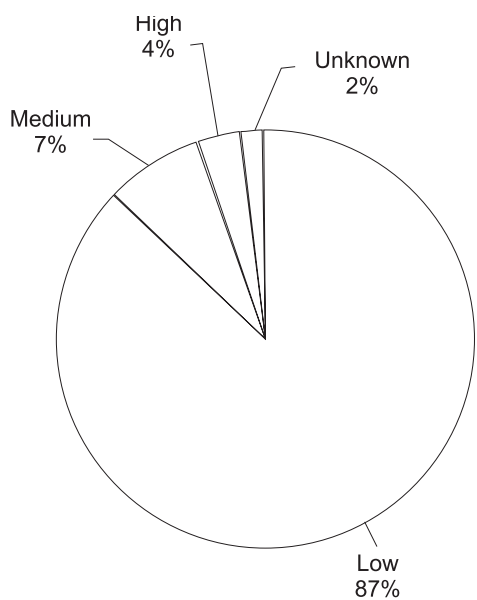

Fig. 5: Impact of alien plant species in KNP.

98, of which eight families collectively contain 125 species (or $35 \%$ of the total) (Fig. 4). The other 90 families contribute to the remaining 245 species.

Impact ranking assigned to the species indicates that $87 \%$ of the species are rated as having a low impact, $7 \%$ medium and $4 \%$ as having a high impact (Fig. 5). Although the perception may be created that invasive species therefore represent a minimal impact to the KNP, the combined effects of only a few invasive species can have major consequences and result in dense stands that cover vast areas.

\section{Conclusion}

Invasive alien plants have been recognised as one of the greatest threats to the biodiversity of the KNP (Braack 1997). In order to address this, proactive work on the prevention of species reaching and infesting the KNP is necessary. Early detection is the single most important step in combating the plants. While still in the early stages of invasion, the plants may be removed before they are able to set seed and become established. 
Updated species lists provide a firm base from which to work and are necessary to determine new invasions in an area as well as the rate of invasion. It is however only a starting point as spatial data is needed to determine the areas invaded, the extent to which they are invaded and the densities of invasions, in order to make meaningful interpretations and recommendations.

\section{Acknowledgements}

Mrs. Guin Zambatis is thanked for identifying numerous plant specimens (over a number of years) for the alien plant section as well as for checking the plant list and adding valuable comments and corrections. My co-authors are thanked for the continued support with often tedious re-checking of the lists.

\section{References}

ANON. 1995. Alien Biota Section records. Scientific Services Department, Skukuza. Unpublished records, South African National Parks.

ANON. 1996. Alien Biota Section records. Scientific Services Department, Skukuza. Unpublished records, South African National Parks.

BraACK, L.E.O. 1997. Vol VII. An objectives hierarchy for the management of the Kruger National Park. A revision of parts of the Management Plan for the Kruger National Park. http://www. parks-sa.co.za.

CoDD, L.E.W. 1951. Trees and shrubs of the Kruger National Park. Memoirs of the Botanical Survey of South Africa 26: 1-192.

FoxCROFT, L.C. 1999. Alien Biota Section records. Scientific Services Department, Skukuza. Unpublished records, South African National Parks.

FoXCROFT, L.C. 2000. Alien Biota Section records. Scientific Services Department, Skukuza. Unpublished records, South African National Parks.

FoxCROFT, L.C. 2001. Alien Biota Section records. Scientific Services Department, Skukuza. Unpublished records, South African National Parks.

FoxCROFT, L.C. \& D.M. RichaRdSON. 2003. Managing alien plant invasions in the Kruger National
Park, South Africa. Pp. 385-403. In: CHILD, L.E., J.H. Brock, G. Brundu, K. Prach, P. PyšeK, P.M. Wade \& M. Williamson (eds.). Plant Invasions: Ecological threats and Management Solutions. Leiden: Backhuys.

Gertenbach, W.P.D. 1985. Alien Plant Section records. Scientific Services Department, Skukuza. Unpublished records, South African National Parks.

HENDERSON, L. 2001. Alien weeds and invasive plants. Pretoria: Plant Protection Research Institute. (Handbook No. 12. Agricultural Research Council).

JOUBERT, S.C.J. 1986. Master plan for the management of the Kruger National Park. National Parks Board, Skukuza, South Africa. http://www.parks-sa.co.za

LOTTER, W.D. 1997. Management proposals for the alien aquatic biological invasions of the Kruger National Park. Scientific Report 10/97. National Parks Board, Republic of South Africa.

LOTTER, W.D. \& J.H. HOFFMANN. 1998. An integrated management plan for the control of Opuntia stricta (Cactaceae) in the Kruger National Park, South Africa. Koedoe 41(1): 63-68.

Macdonald, I.A.W. \& W.P.D. Gertenbach. 1988. A list of alien plants in the Kruger National Park. Koedoe 31: 137-150.

MCNeELY, J.A. 2000. Global strategy for addressing the problem of invasive alien species. A result of the Global Invasive Species Programme (GISP). Unpublished report. IUCN- The World Conservation Union, Switzerland.

Noss, R.F. 1990. Indicators for monitoring biodiversity: a hierarchical approach. Conservation Biology 4: 355-364.

OBERMEIJER, A.A. 1937. A preliminary list of the plants found in the Kruger National Park. Annals of the Transvaal Museum 17(4): 185-227.

Olckers, T \& M.P. Hill (eds). 1999. Biological control of weeds in South Africa (1990-1998). African Entomology Memoir No.1.

Richardson, D.M., P. Pysek, M. Rejmanek, M.G. Barbour, F.D. Panetta \& C.J. West. 2000. Naturalization and invasion of alien plants: concepts and definitions. Diversity and Distributions 6: 93-107.

VAN DER SCHIJFF, H.P. 1957. Ekologiese studie van die flora van die Nasionale Krugerwildtuin. D.Sc. thesis, Potchefstroom University for Christian Higher Education, Potchefstroom.

VAN DER SCHIJFF, H.P. 1969. A checklist of the plants of the Kruger National Park. Publikasies van die Universiteit van Pretoria, Nuwe reeks 53: 1-100. 


\section{Appendix 1}

List of plants not classed as aliens

1. Centella asiatica (L.) Urb.

2. Trichodesma zeylanicum (Burm.) R. Br.

3. Ocimum americanum L. var. americanum

4. Hibiscus cannabinus L. var. cannabinus

5. Sida alba $\mathrm{L}$.

6. Sida cordifolia L.

7. Crotalaria sphaerocarpa Perr. ex DC. subsp. sphaerocarpa

8. Vigna oblongifolia A. Rich. var. oblongifolia

9. Dodonaea angustifolia L.f.

10. Striga asiatica (L.) Kuntze

11. Withania somnifera (L.) Dunal

12. Triumfetta pentandra A. Rich. var. pentandra

13. Triumfetta rhomboidea Jacq. var. rhomboidea 